\title{
A nurse led intermediate care package in patients who have been hospitalised with an acute exacerbation of chronic obstructive pulmonary disease
}

\author{
M Sridhar, ${ }^{*}$ R Taylor, S Dawson, N J Roberts, M R Partridge
}

\section{See editorial on p 187}

- Appendix A is published online only at http://thorax.bmj. com/content/vol63/issue3

NHLI Division, Faculty of Medicine, Imperial College London, Charing Cross Campus, London, UK

\section{Correspondence to:}

Professor M R Partridge, NHLI Division, Faculty of Medicine, Imperial College London, Charing Cross Campus, London W6 8RP UK; m.partridge@imperial.ac.uk

*Dr Sridhar died on 29 june 2006

Received 8 January 2007 Accepted 12 August 2007 Published Online First 27 September 2007

\begin{abstract}
Objectives: To determine the effects of a nurse led intermediate care programme in patients who have been hospitalised with an acute exacerbation of chronic obstructive pulmonary disease (AECOPD).

Design: Randomised controlled trial.

Setting: Community and hospital care in west London. Participants: 122 patients with COPD.

Intervention: A care package incorporating initial pulmonary rehabilitation and self-management education, provision of a written, personalised COPD action plan, monthly telephone calls and 3 monthly home visits by a specialist nurse for a period of 2 years.
\end{abstract}

Main outcome measure: Hospital readmission rate. Secondary outcomes: Unscheduled primary care consultations and quality of life.

Results: There were no differences in hospital admission rates or in exacerbation rates between the two groups. Self-management of exacerbations was significantly different and the intervention group were more likely to be treated with oral steroids alone or oral steroids and antibiotics, and the initiators of treatment for exacerbations were statistically more likely to be the patients themselves. 12 patients in the control group died during the 2 year period, eight as a result of COPD, compared with six patients in the intervention group, of whom one died from COPD. This is a significant difference. When the numbers were adjusted to reflect the numbers still alive at 2 years, in the intervention group patients reported a total of 171 unscheduled contacts with their general practitioner (GP) and in the control group, 280 contacts. The number needed to treat was 0.558 - ie, for every one COPD patient receiving the intervention and selfmanagement advice, there were 1.79 fewer unscheduled contacts with the GP.

Conclusions: An intermediate care package incorporating pulmonary rehabilitation, self-management education and the receipt of a written COPD action plan, together with regular nurse contact, is associated with a reduced need for unscheduled primary care consultations and a reduction in deaths due to COPD but did not affect the hospital readmission rate.

Chronic obstructive pulmonary disease (COPD) represents a global health burden and will move from 12th place to be the fifth largest cause of disability adjusted life years lost by $2020 .{ }^{1}$ In the UK, 30000 deaths per year are attributed to COPD, over $5 \%$ of all deaths, ${ }^{2}$ and up to one in eight emergency hospital admissions may be due to COPD. ${ }^{3}$ Much of the morbidity and mortality related to the condition results from exacerbations of the disease, and frequent exacerbations are associated with more rapid decline in lung function. ${ }^{4}$ These exacerbations are much feared by patients who dislike their impact on everyday life and fear of being housebound, bedridden or hospitalised. ${ }^{56}$ Previous research has focused on optimal therapeutic strategies for both the prevention $^{7-10}$ and treatment of acute exacerbations ${ }^{11}$ and also on the effectiveness of care interventions such as "hospital at home" and early discharge schemes for those having acute exacerbations of COPD. ${ }^{12} 13$ A systematic review of the effectiveness of innovations in nurse led management has concluded that there is little evidence to date to support such interventions, but the authors conclude that the data are too sparse to be certain, and none of the studies extended beyond a duration of 12 months. ${ }^{14}$ There is a similar lack of evidence to show whether self management education alters outcomes in COPD. ${ }^{15}$

We have undertaken a randomised controlled trial to determine the effects of a nurse led intermediate care programme in the management of patients who have been hospitalised with an acute exacerbation of COPD. The care package incorporated initial pulmonary rehabilitation followed by an emphasis on self-management education and nurse follow-up for 2 years.

\section{METHODS}

A list of patients who had been admitted to Charing Cross and Hammersmith Hospitals, London, UK, between 1 January 2000 and 31 August 2004 with the main reason for admission being coded on discharge as having been due to an acute exacerbation of COPD was obtained from the hospital database. The clinical notes of these patients were reviewed by the investigators using a proforma. If thought to represent a suitable patient, the case notes were discussed and, where necessary, further information obtained. Exclusion criteria included significant comorbidity such as severe heart disease or cancer, or any condition that would preclude participation in the physical therapy component of a pulmonary rehabilitation programme. None of the patients had previously undertaken a pulmonary rehabilitation programme. Those patients thought to be suitable were sent a letter inviting them to participate in the study and those who responded were invited for initial assessment and, if still suitable and 
agreeable, randomised to the intervention or usual care groups.

The study intervention involved all patients initially participating in a hospital based pulmonary rehabilitation programme consisting of two attendances per week for 4 weeks. During this visit, the patients received general education about their disease and its treatment ( $1 \mathrm{~h}$ per session) and underwent an individualised physical training programme ( $1 \mathrm{~h}$ per session). Following completion of the pulmonary rehabilitation programme, the patients received a baseline home visit by a specialist respiratory nurse, and during this first visit, the patients were given a personalised written COPD action plan (a copy of which is shown in appendix A online). This contained both lifestyle advice and advice about their usual medication, and gave specific advice about when the patient should start a course of antibiotics and when they should start a course of steroid tablets. The general practitioners of these patients were requested to provide for the patient reserve supplies of these medications.

Subsequently, those in the intervention group had monthly telephone calls from the respiratory nurses and a home visit every 3 months. During each interview and visit, the nurses undertook a structured approach to history taking and during home visits measured pulse and respiratory rate, oxygen saturation and end-tidal carbon monoxide. Spirometry was performed at baseline and after 12 and 24 months. During both telephone and home visits, they reinforced advice regarding treatments, smoking cessation if relevant, the need to continue their exercise therapy and discussed and reinforced the selfmanagement education which had been given and offered encouragement for successful self-treatment. The patients were also given written advice about the treatment of COPD which they were asked to show to their doctor if they underwent any unscheduled healthcare.

Patients in the control group received usual care from their primary care physician, or secondary care and/or the respiratory nursing service as appropriate. No attempt was made to influence this care. Patients in both the control and intervention groups had their use of healthcare monitored by monthly telephone self-report verified by confirmation of the general practice and hospital records. General practice records alone were not used because they do not always contain a record of hospital admissions and it is not always possible to tell which consultation within primary care was scheduled and which was unscheduled. Corroboration of patient self-reported general practitioner (GP) consultations was undertaken by the GPs themselves from their records. Corroboration of patient selfreported hospital admissions was undertaken by the respiratory research nurses against local hospital records. A copy of the death certificate was requested for all patients who died.

Quality of life was assessed using the Chronic Respiratory Questionnaire ${ }^{16}{ }^{17}$ at baseline and three further times during the subsequent 2 years.

The study was approved by the Riverside Research Ethics Committee.

\section{Statistical analysis}

The primary end point for our trial was to be hospital readmission rate with secondary outcomes being unscheduled consultations with GP and quality of life. Retrospective review of previous local hospital admission rates suggested that over a 2 year period, 579 patients might accrue a total of 1180 admissions (mean 2.04 admissions per patient). We calculated that we would need a study of 88 patients to have an $80 \%$ chance of detecting a difference $95 \%$ readmission in usual care versus $75 \%$ in the intervention group), using a two sided alpha $=0.05$. All statistical analysis was carried out using the software program SPSS (V.12.0). For all analyses, $\chi^{2}$ tests, the Mann-Whitney test, independent or paired t tests were used.

\section{RESULTS}

There were 2305 admissions to Hammersmith Hospitals NHS Trust between 1 January 2000 and 31 August 2004. Many of those were multiple admissions and the total number of patients admitted with an acute exacerbation of COPD in that period was 1247. A total of 507 of these patients had died at the time we began recruiting to this study and of the 740 who were alive, 166 lived outside our area and were not therefore able to attend the pulmonary rehabilitation programme if randomised to intervention. This left 574 patients who were assessed. Two hundred and seventy-seven of these were thought to be unsuitable for the reasons shown in table 1.

Of the 297 patients who were suitable for inclusion in the trial, $120(40.4 \%)$ responded that they did not wish to take part in the trial, $55(18.5 \%)$ did not reply and 122 (41\%) patients were suitable, and were recruited and randomised by the use of random numbers to the intervention or control group. These data are summarised in the consort diagram in fig 1. Demographic data and details of severity, treatment, unscheduled use of healthcare and quality of life for all patients at baseline and at the end of year 2 is shown in table 2 .

From table 2 it can be seen that at baseline, the control and intervention groups were well matched for age, gender, severity of disease, previous hospitalisation rate, breathlessness scores, weight, smoking habits and use of home oxygen. Both groups had similar numbers of initial and persisting smokers and breathlessness scores worsened during the course of the study in both groups. Lung function appeared to decline to a greater degree in the control group than in the intervention group, but this difference was not statistically significant. At baseline, similar proportions of patients were receiving long acting beta agonist bronchodilators and anticholinergic agents, and the majority of patients in both the intervention group and in the control group were taking inhaled steroids at entry to the trial. At the end of the trial, patients in the intervention group were statistically more likely to be on a long acting inhaled beta agonist or a short or long acting anticholinergic agent in the intervention group, compared with the control group.

At the beginning of the trial, $5 \%$ of the intervention group and $11.5 \%$ of the control group had a reserve supply of antibiotics; corresponding values for steroid tablets were $5 \%$ and $7 \%$, respectively. After the intervention, over $95 \%$ had both types of reserve treatments available, compared with the control group, where $17 \%$ had antibiotics available at the end of 1 year and $25 \%$ at the end of 2 years. Sixteen per cent of the control

Table 1 Reasons for patients being regarded as unsuitable to be included in the trial $(n=277)$

Alternative diagnosis, no evidence of COPD: 122 (44.1\%)

These were mainly because perusal of the notes gave clear evidence of anothe major pulmonary condition, such as asthma, diffuse parenchymal lung disease or bronchiectasis

- Psychosocial problems and significant cognitive impairment: 68 (28.5\%)

(eg, dementia, blindness, alcohol abuse, psychiatric illness, homelessness or in prison)

- Severe limiting comorbidity involving other major organ systems: 50 (18.1\%) (mainly cardiac but also cancer and alcohol related liver disease, etc)

- Factors limiting mobility and locomotion: 37 (13.3\%)

(housebound, wheelchair bound, previous cerebrovascular accident, severe arthritis) 
Figure 1 Flowchart of patient recruitment to the study.

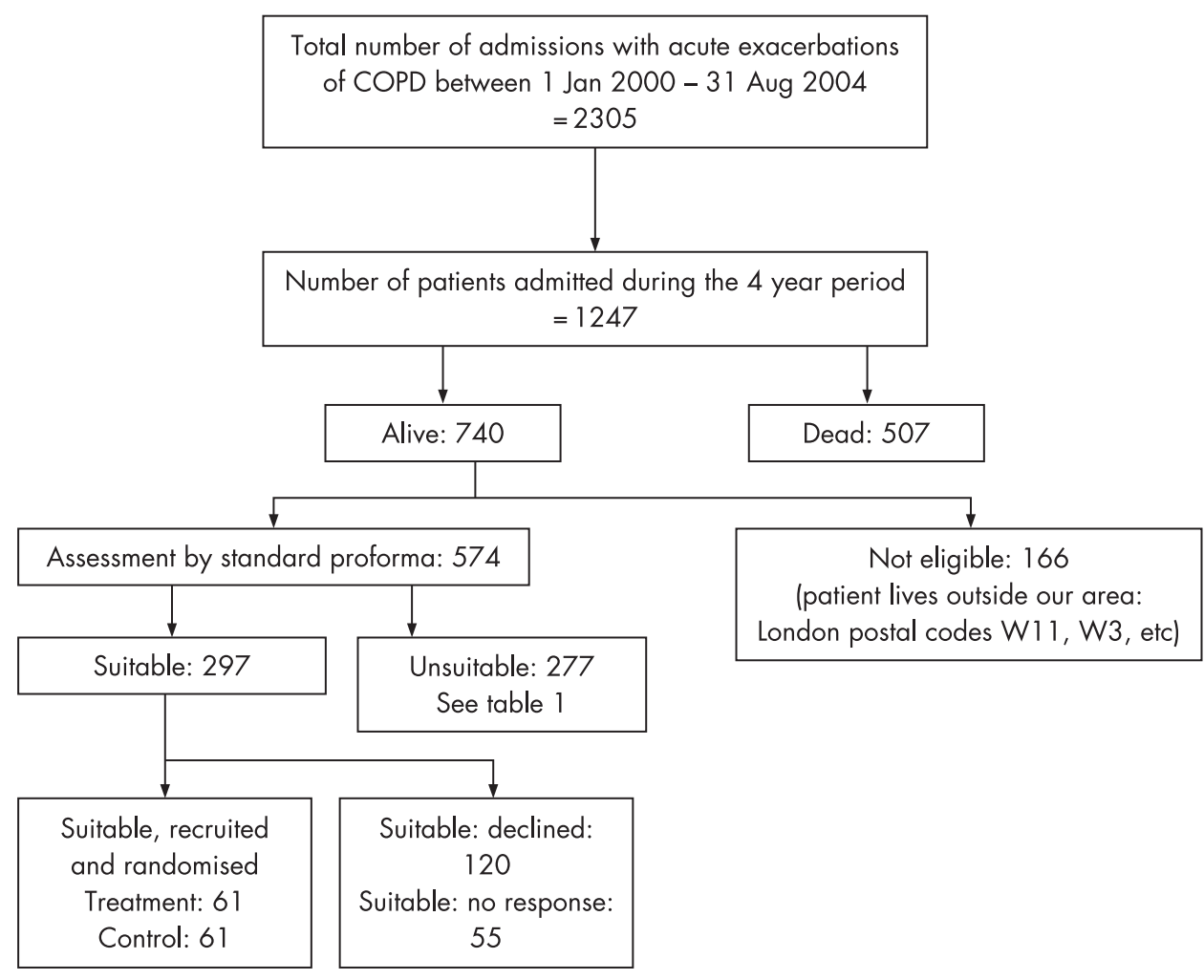

group had a reserve supply of steroid tablets at the end of 2 years. There were no differences in exacerbation rates between the two groups (an exacerbation being defined as an unscheduled need for healthcare, or need for steroid tablets, or antibiotics for worsening of their COPD), nor was there a difference in the total number of exacerbations per group over the 2 year period. There was also no difference in the total number of hospital admissions or in the number of patients having an admission to hospital during the 2 year period. Because this could have been influenced by differences in death rates, this was also analysed as days alive and out of hospital in the two groups, but there was no statistically significant difference. Self-management of exacerbations was however significantly different and patients in the intervention group were more likely to have exacerbations treated with oral steroids alone or oral steroids and antibiotics than the control group, who were more likely to be treated with antibiotics alone. The initiator of treatment for exacerbations was statistically more likely to be the patient themselves in the intervention group and the GP in the control group.

Twelve patients in the control group died during the 2 year period, eight as a result of COPD, compared with six patients dying in the intervention group, of which one died from COPD. The number dying from COPD in the control group was significantly higher both as a proportion of the total deaths and as a proportion of all patients in the trial compared with those in the intervention group. The non-COPD deaths included four deaths due to pneumonia (three in the control group and one in the intervention group), one due to metastatic lung cancer, one due to cerebral haemorrhage, two due to coronary artery disease and one due to septic shock. All but two patients died in hospital. The stated cause of death was confirmed by acquisition of copies of the death certificates in all but one case. One patient died on a cruise ship off the coast of West Africa and death was reported by relatives to have been due to worsening of their lung condition over several days following exposure to adverse environmental conditions. When the numbers in the intervention and control groups were adjusted to reflect the numbers still alive, it can be seen that at 2 years, 55 of 61 patients in the intervention group were still alive, and these patients had reported a total of 171 unscheduled contacts with their GP. In the control group, 49 of the 61 patients were still alive, and they had had 280 contacts with their GP. The number needed to treat, therefore, was 0.558 -ie, for every one COPD patient receiving self-management education, there was 1.79 less unscheduled contacts with the GP. The health economic costs of the pulmonary rehabilitation programme are shown in table 3, and suggest that the costs of the intervention were only very slightly greater per patient than the savings on unscheduled primary healthcare (£153 compared with £142).

Within the Chronic Respiratory Questionnaire there was a statistical and clinically significant worsening in the mean dyspnoea score in both the intervention and control groups from baseline to end of year 2, and the mean mastery score improved in the intervention group but this change was not clinically significant.

To ensure that any differences did not reflect differences in routine healthcare received, data in table 4 show that equal numbers of patients received primary care alone in both the intervention and control groups but some in the control group also received care from the local respiratory nursing service. They may have been offered care which contained some similarities to that offered by the research respiratory nurses.

\section{DISCUSSION}

The proportion of patients who had been admitted to hospital with an exacerbation of COPD who were eligible for and consented to take part in this trial was lower than anticipated. This was because of both polymorbidity and non-consent, and 
Table 2 Data for patients in the intervention and control groups at entry to the trial, and for those alive, at the end of year 2

\begin{tabular}{|c|c|c|c|c|c|c|}
\hline \multirow[b]{2}{*}{ Variables } & \multicolumn{2}{|l|}{ Treatment $(n=61)$} & \multicolumn{2}{|l|}{ Control $(n=61)$} & \multirow[b]{2}{*}{$\begin{array}{l}\text { Percentage } \\
\text { difference: }\end{array}$} & \multirow[b]{2}{*}{ p Value } \\
\hline & $\begin{array}{l}\text { Baseline }(n=61) \\
(\%(n))\end{array}$ & $\begin{array}{l}\text { Year } 2(n=55) \\
(\%(n))\end{array}$ & $\begin{array}{l}\text { Baseline }(n=61) \\
(\%(n))\end{array}$ & $\begin{array}{l}\text { Year } 2(n=49) \\
(\%(n))\end{array}$ & & \\
\hline Males (\%) & $49.2(30 / 61)$ & & $49.2(30 / 61)$ & & 0 & NS \\
\hline BMI (median (range)) & $25.0(14-38)$ & & $24(16-40)$ & & 1 & \\
\hline \multicolumn{7}{|l|}{ Smoking status } \\
\hline Current smoker & $29.5(18 / 61)$ & $29.1(16 / 55)$ & $19.7(12 / 61)$ & $22.4(11 / 49)$ & 6.7 & 0.426 \\
\hline \multicolumn{7}{|l|}{ Home $\mathrm{O}_{2}$} \\
\hline Yes (\%) & $19.7(12 / 61)$ & $25.4(14 / 55)$ & $21.3(13 / 61)$ & $26.5(13 / 49)$ & -1.1 & 0.901 \\
\hline Cylinder & $33.3(4 / 12)$ & $28.6(4 / 14)$ & $46.1(6 / 13)$ & $46.1(6 / 13)$ & -17.5 & \\
\hline Concentrator & $66.6(8 / 12)$ & $71.4(10 / 14)$ & $53.8(7 / 13)$ & $53.8(7 / 13)$ & 17.6 & \\
\hline $\mathrm{FEV}_{1}$ (mean (SD)) & $1.04(0.44)$ & $0.95(0.42)$ & $1.17(0.49)$ & $1.06(0.44)$ & -0.16 & $0.186^{*}$ \\
\hline FVC (mean (SD)) & $2.12(0.74)$ & $1.98(0.65)$ & $2.2(0.77)$ & $2.1(0.79)$ & -0.12 & $0.387^{*}$ \\
\hline Admission in the 2 y prior to recruitment $(\%(\mathrm{n}))$ & $80.3(49 / 61)$ & & $68.8(42 / 61)$ & & 11.5 & 0.145 \\
\hline No of admissions/patient/2 y (median (range)) & $1.0(0-6)$ & & $1.0(0-6)$ & & & \\
\hline \multicolumn{7}{|l|}{ LABA prescription } \\
\hline Yes $(\%)$ & $67.2(41 / 61)$ & $92.7(51 / 55)$ & $63.9(39 / 61)$ & $71.4(35 / 49)$ & 21.3 & 0.004 \\
\hline LABA inhaler alone & $29.3(12 / 41)$ & $0.00(0 / 51)$ & $33.3(13 / 39)$ & $8.6(3 / 35)$ & 8.6 & \\
\hline LABA and ICS combination inhaler & $70.7(29 / 41)$ & $100(51 / 51)$ & $66.7(26 / 39)$ & $91.4(32 / 35)$ & 8.6 & \\
\hline \multicolumn{7}{|l|}{ ICS prescription } \\
\hline Yes $(\%)$ & $88.5(54 / 61)$ & $94.5(52 / 55)$ & $80.3(49 / 61)$ & $100.0(49 / 49)$ & -5.5 & 0.097 \\
\hline Inhaled ICS alone & $46.3(25 / 54)$ & $1.9(1 / 52)$ & $46.9(23 / 49)$ & $24.5(12 / 49)$ & -22.6 & \\
\hline ICS and LABA combination inhaler & $53.7(29 / 54)$ & $98.0(51 / 52)$ & $53.1(26 / 49)$ & $65.3(32 / 49)$ & 32.7 & \\
\hline \multicolumn{7}{|l|}{ Anticholinergic prescription } \\
\hline Yes $(\%)$ & $73.7(45 / 61)$ & $89.1(49 / 55)$ & $63.9(39 / 61)$ & $65.3(32 / 49)$ & 23.8 & 0.004 \\
\hline Admission in study period $((\%$ (n)) & & $52.7(29 / 55)$ & & $48.9(24 / 49)$ & & 0.361 \\
\hline No of admissions per patient (median (range)) & & $0(0-13)$ & & $0(0-5)$ & & \\
\hline Days alive and out of hospital/2 y & & $41400 / 44530$ & & $39578 / 44530$ & & $0.705^{*}$ \\
\hline Total & & $(93.0 \%)$ & & $(88.9 \%)$ & & \\
\hline Median (range) & & $724(244-730)$ & & $730(19-730)$ & & \\
\hline \multicolumn{7}{|l|}{ Self-management of COPD } \\
\hline Reserve oral antibiotics prescribed & $4.9(3 / 61)$ & $92.7(51 / 55)$ & $11.5(7 / 61)$ & $24.5(12 / 49)$ & 68.2 & $<0.001$ \\
\hline Reserve oral steroids prescribed & $4.9(3 / 61)$ & $92.7(51 / 55)$ & $6.5(4 / 61)$ & $16.3(8 / 49)$ & 76.4 & $<0.001$ \\
\hline No of patients who reported an exacerbation & & $86.9(53 / 61)$ & & $86.9(53 / 61)$ & 0 & \\
\hline Treated with oral antibiotics only & & $36.2(161 / 445)$ & & $63.8(233 / 364)$ & -27.6 & $<0.001$ \\
\hline Treated with oral steroids only & & $19.8(88 / 445)$ & & $7.7(28 / 364)$ & 12.1 & $<0.001$ \\
\hline Treated with oral antibiotics and steroids & & $44.0(196 / 445)$ & & $28.3(103 / 364)$ & 15.7 & $<0.001$ \\
\hline \multicolumn{7}{|l|}{ Who initiated treatment for exacerbation? } \\
\hline Self & & $43.1(192 / 445)$ & & $10.4(38 / 364)$ & 32.7 & $<0.001$ \\
\hline Research nurse & & $6.3(28 / 445)$ & & $0(0 / 364)$ & 6.3 & $<0.001$ \\
\hline GP & & $31.5(140 / 445)$ & & $68.7(250 / 364)$ & -37.2 & $<0.001$ \\
\hline A\&E doctor & & $0.9(4 / 445)$ & & $2.5(9 / 364)$ & -1.6 & 0.077 \\
\hline Outpatients clinic doctor & & $2.9(13 / 445)$ & & $5.2(19 / 364)$ & -2.3 & 0.095 \\
\hline Inpatient hospital doctor & & $15.3(68 / 445)$ & & $13.5(49 / 364)$ & 1.8 & 0.464 \\
\hline Total No of unscheduled GP visits/contact & & 171 & & 280 & -109 & $<0.05^{*}$ \\
\hline Telephonic consultation & & $9.9(17 / 171)$ & & $3.5(10 / 280)$ & 6.4 & 0.006 \\
\hline Practice attendance & & $67.8(116 / 171)$ & & $88.2(247 / 280)$ & -20.4 & $<0.001$ \\
\hline Home visit & & $22.3(38 / 171)$ & & $8.2(23 / 280)$ & 14.1 & $<0.001$ \\
\hline Disease Specific OoL Questionnaire: CRO & $\begin{array}{l}47 \\
\text { (fully completed) }\end{array}$ & $\begin{array}{l}47 \\
\text { (fully completed) }\end{array}$ & $\begin{array}{l}40 \\
\text { (fully completed) }\end{array}$ & $\begin{array}{l}40 \\
\text { (fully completed) }\end{array}$ & & \\
\hline
\end{tabular}


Table 2 Continued

\begin{tabular}{|c|c|c|c|c|c|c|}
\hline \multirow[b]{2}{*}{ Variables } & \multicolumn{2}{|l|}{ Treatment $(n=61)$} & \multicolumn{2}{|l|}{ Control $(n=61)$} & \multirow[b]{2}{*}{$\begin{array}{l}\text { Percentage } \\
\text { difference: }\end{array}$} & \multirow[b]{2}{*}{ p Value } \\
\hline & $\begin{array}{l}\text { Baseline }(n=61) \\
(\%(n))\end{array}$ & $\begin{array}{l}\text { Year } 2(n=55) \\
(\%(n))\end{array}$ & $\begin{array}{l}\text { Baseline }(n=61) \\
(\%(n))\end{array}$ & $\begin{array}{l}\text { Year } 2(n=49) \\
(\%(n))\end{array}$ & & \\
\hline Dyspnoea & $3.55(1.12)$ & $2.83(1.21) \uparrow$ & $3.49(1.26)$ & $2.65(1.23)$ & & $\begin{array}{l}\text { Tp }<0.05 \\
\text { (paired t-test) } \\
\text { between } \\
\text { baseline and } 2 y\end{array}$ \\
\hline Fatigue & $3.62(1.26)$ & $3.68(1.35)$ & $3.59(1.51)$ & $3.24(1.11)$ & & \\
\hline Mastery & $4.71(1.26)$ & $5.14(1.33) \oplus$ & $4.71(1.46)$ & $4.44(1.45)$ & & \\
\hline \multicolumn{7}{|l|}{ Emotional domain } \\
\hline Total score & $16.46(4.05)$ & $16.41(3.94)$ & $16.18(4.56)$ & 14.37 (3.97) & & \\
\hline
\end{tabular}

*Mann Whitney, †Student $t$ test.

\$Percentage difference at 2 years between intervention and control (treatment - control).

$\S$ Control versus treatment end of year 2 , all $\chi^{2}$ statistical analysis except where stated.

$\mathrm{BMI}$, body mass index; COPD, chronic obstructive pulmonary disease; CRO, Chronic Respiratory Questionnaire; FEV 1 , forced expiratory volume in 1 s; FVC, forced vital capacity; GP, general practitioner; ICS, inhaled corticosteroids; LABA, long acting beta-2 agonist.

Table 3 Health economic costs of the pulmonary rehabilitation programme

\begin{tabular}{|c|c|c|}
\hline & Treatment $(n=61)$ & Control $(n=61)$ \\
\hline GP unscheduled contacts & 171 & 280 \\
\hline Cost of GP consultations (Curtis 2006)* & f5301 & f8680 \\
\hline $\begin{array}{l}\text { Cost of self management education } \\
\text { ( } 1 \mathrm{hr} \text { group sessions } \mathrm{n}=8 \text { and } 1 \text { home visit } \\
\text { (approx } 70 \text { min)) }\end{array}$ & 81 nurse hours $=£ 2511$ & $\begin{array}{l}\text { No self management education/ } \\
\text { home visits given }\end{array}$ \\
\hline Travel costs for home visits (Netten 2006) & £37.21 & $\mathrm{f0}$ \\
\hline \multirow[t]{2}{*}{ Routine follow-up calls for patients (by nurses) } & 547 calls, 48 hours (total length) & No follow-up calls \\
\hline & Cost $£ 28.82$ & Cost $f 0$ \\
\hline Nurse costs for telephone calls & f1488 & \\
\hline \multirow[t]{2}{*}{ Total } & $\begin{array}{l}\text { Nurse costs }(f 2511+f 1488)+ \\
\text { telephone calls }(f 28.82)+ \\
\text { unscheduled healthcare costs } \\
\text { (f5301) }\end{array}$ & \\
\hline & f9328.82 & f8680.00 \\
\hline Approx cost of intervention (per patient) & f66 & \\
\hline $\begin{array}{l}\text { Mean cost of unscheduled healthcare for all in the } \\
\text { intervention group }\end{array}$ & $(171 \times £ 31) / 61=£ 86.90$ & $(280 \times £ 31) / 61=£ 142.30$ \\
\hline Total cost (per patient) & £153 & $£ 142.30$ \\
\hline
\end{tabular}

the latter was due more to the intervention, including pulmonary rehabilitation, than to it being a research trial. ${ }^{18}$ As a result, recruitment was lower than expected but neither the total number of readmissions nor the number of patients having an admission during the 2 year follow-up period differed between the intervention and control groups. This result is thus consistent with a previous review ${ }^{14}$ but extends our knowledge to show that the same applies if the intervention continues for 2 years. The secondary outcome of rate of

Table 4 Care received by those in the intervention and control groups

\begin{tabular}{lll}
\hline & $\begin{array}{l}\text { Intervention } \\
\text { group }\end{array}$ & $\begin{array}{l}\text { Control } \\
\text { group }\end{array}$ \\
\hline Primary care & $31 / 61$ & $36 / 61$ \\
$1^{\prime}$ care doctors only & 31 & 32 \\
$1^{\prime}$ care doctors and RNS & 0 & 4 \\
Secondary care & $30 / 61$ & $25 / 61$ \\
$1^{\prime}$ and 2' care doctors only & 30 & 16 \\
$1^{\prime}$ and 2' care doctors and RNS & 0 & 9 \\
\hline
\end{tabular}

RNS, Respiratory Nursing Service. unscheduled GP consultations was significantly less in the intervention group.

It thus looks as though the self-management education part of the intervention, given in group format during the pulmonary rehabilitation programme and individually by the nurse subsequently, led to intervention patients being more likely to have received supplies of antibiotics and steroids and more likely to start these themselves to treat an exacerbation than the control group.

Unexpectedly, we showed a significant reduction in deaths due to COPD in the intervention group. We acknowledge the difficulties around the accuracy of death certificates. However, this reduction in death rate could be explained by a reduction in the severity of exacerbations as a result of self-treatment with antibiotics and steroid tablets and it is probable that the ready availability of reserve medications leads to their prompter use, and earlier treatment of exacerbations has been shown to be associated with improved outcomes. ${ }^{19}$ A less likely explanation for a reduced death rate would be differences in routine inhaler therapy in the intervention group compared with the control group. While controversial, there have been suggestions that the use of inhaled steroids ${ }^{20-24}$ might be associated with a reduction 
in mortality. However, essentially, all patients in both the intervention and control arms in our trial were receiving inhaled steroids, but there were differences in the use of anticholinergic agents and long acting beta agonists in our intervention arm and this may have contributed to increased survival. ${ }^{8924}$ However, most of those who died were also on these medications. The likelihood that the reduction in mortality instead reflected prompt self-treatment would be consistent with review of 11 randomised controlled trials comparing antibiotics with placebo for acute worsening of COPD, which showed that regardless of antibiotic used, antibiotic therapy significantly reduced mortality. ${ }^{25}$ Such a reduction in mortality as a result of steroid tablet use has not been demonstrated. ${ }^{26}$ Why we demonstrated a significant reduction in unscheduled need for primary healthcare and a reduction in mortality, but no reduction in hospital admission rates, is less clear. Selfadministration of antibiotics (and steroid tablets) may have reduced the severity of exacerbations sufficiently to reduce mortality without influencing the need or otherwise for admission to hospital, which is in any way likely to be influenced by social factors such as isolation, depression and available support in the home.

There are clearly still many unknowns with regard to what constitutes optimal care for those with COPD. We included pulmonary rehabilitation within our intermediate care package because it contains elements of exercise therapy, group support and group education, and has been shown to beneficially affect outcomes such as quality of life, exercise ability and breathlessness scores. It has not however been shown conclusively to affect hospitalisation rate, mortality or primary care consultation rates. ${ }^{27}$ The improvements in the latter two outcomes in our study are therefore unlikely to reflect incorporation of pulmonary rehabilitation within the intervention package. Regular follow-up by nurses in this study has again failed to demonstrate a benefit in terms of reduction in hospital admission rates and this result is almost identical to a shorter study from this hospital 20 years ago $^{28}$ However, we have demonstrated that an intervention which includes group advice regarding self-management education, followed by the issuing to each patient of a personalised action plan leads to an alteration in self-management behaviour and reduced need for unscheduled primary care. Previously, the case for self-management education in COPD was not proven. ${ }^{15}$ Studies reported subsequent to that review, and subsequent to us starting this study, have shown conflicting results. One group ${ }^{29}$ showed no differences in quality of life scores or walking distance and no reduction in exacerbation rate following self-management education, while another demonstrated a significant reduction in hospital admissions, emergency department visits and physicians visits. ${ }^{30}$ In the latter study, however, and indeed in our own, it is difficult to be certain which of several parts of a complex package achieved which benefit. The relationship between possession of antibiotics and oral steroids, their selfadministration and the reduced need for unscheduled primary care in our study does appear to be causally related. One explanation for differences in previous studies may lie in the way in which the personalised self-management advice was given. In asthma, where there is overwhelming evidence in favour of self-management education, ${ }^{31}{ }^{32}$ written action plans are a key component. In the systematic review of self-management in COPD, ${ }^{15}$ only two studies involved patients receiving a written action plan, and study of the action plans used in those two studies shows that one was a typical asthma action plan ${ }^{33}$ and did not, for example, include any advice to the patient about antibiotics. The other study ${ }^{34}$ did include an action plan which included advice as to when to start antibiotics and this did show an alteration in patient usage of antibiotics and steroids but the study was not powered to show a change in outcome.

A subsequent Cochrane review ${ }^{35}$ has suggested that use of action plans can alter self-management behaviour in those with COPD but did not lead to any hard outcomes. Our study does show that self-management education can be associated with change in patient behaviour and a reduction in the need for urgent primary care, and this plus follow-up by nurses and possibly optimisation of inhaled therapy can be associated with reduced mortality due to COPD.

Acknowledgements: We acknowledge with thanks the help of Ms Catherine Taylor and Ms Bumni Abedajo in the undertaking of the pulmonary rehabilitation programme.

Funding: The study was funded by The Health Foundation.

Competing interests: None.

Ethics approval: yes.

Trial registration number: NCT00129779

\section{REFERENCES}

1. Murray CJL, Lopez AD. Alternative projections of mortality and disability by cause 1990-2020: Global Burden of Disease Study. Lancet 1997:349:1498-504.

2. Office for National Statistics. Mortality statistics: cause, 1999. London: HMSO, 2000:DH2(26).

3. Chronic obstructive pulmonary disease. National Clinical Guideline on Management of Chronic Obstructive Pulmonary Disease in Adults in Primary and Secondary Care. The National Collaborating Centre for Chronic Conditions. Thorax 2004;59(Suppl 1):1-232.

4. Donaldson GC, Seemungal TA, Bhowmik A, et al. Relationship between exacerbation frequency and lung function decline in chronic obstructive pulmonary disease. Thorax 2002:57:847-52.

5. Haughney J, Partridge MR, Vogelmeier C, et al. Exacerbations of COPD: quantifying the patient's perspective using discrete choice modelling. Eur Respir J 2005;26:623-9.

6. Kessler R, Stahl E, Vogelmeier C, et al. Patient understanding, detection and experience of COPD exacerbations: an observational, interview-based study. Chest 2006;130:133-42.

7. Calverley P, Pauwels R, Vestbo J, et al. Combined salmeterol and fluticasone in the treatment of chronic obstructive pulmonary disease - a randomised controlled trial. Lancet 2003;361:449-56.

8. Szanfranski W, Cukier A, Ramirez A, et al. Efficacy and safety of budesonide/ formoterol in the management of chronic obstructive pulmonary disease. Eur Respir $J$ 2003;21:74-81.

9. Calverley PM, Boonsawat W, Cseke Z, et al. Maintenance therapy with budesonide and formoterol in chronic obstructive pulmonary disease. Eur Respir J 2003;22:91219.

10. Barr RG, Bourbeau J, Camargo CA, et al. Tiotropium for stable chronic obstructive pulmonary disease: a meta-analysis. Thorax 2006;61:854-62.

11. Currie GP, Wedzicha JA. Acute exacerbations. ABC of chronic obstructive pulmonary disease. BMJ 2006;333:87-9.

12. Cotton MN, Bucknall CE, Dagg KD, et al. Early discharge for patients with exacerbations of chronic obstructive pulmonary disease: a randomised controlled trial. Thorax 2000;55:902-6.

13. Davies L, Wilkinson M, Bonner S, et al. "Hospital at home" versus hospital care in patients with exacerbations of chronic obstructive pulmonary disease: Prospective randomised controlled trial. BMJ 2000;221:1265-8.

14. Taylor SJC, Candy B, Bryar RM, et al. Effectiveness of innovation in nurse-led chronic disease management for patients with chronic obstructive pulmonary disease: A systematic review of evidence. BMJ 2005;331:485.

15. Monninkhof $\mathbf{E}$, van der Valk P, van der Palen J, et al. Self management education for patients with chronic obstructive pulmonary disease: a systematic review. Thorax 2003:58:394-8.

16. Wyrwich KW, Filn SD, Tierney WM, et al. Clinically important changes in healthrelated quality of life for patients with chronic obstructive pulmonary disease: an expert consensus panel report. J Gen Intern Med 2003:18:196-202.

17. Guyatt GH, Berman LB, Townsend $M$, et al. A measure of quality of life for clinical trials in chronic lung disease. Thorax 1987;42:773-8.

18. Taylor R, Dawson S, Roberts N, et al. Why do patients decline to take part in a research project involving pulmonary rehabilitation? Respir Med 2007;101:1942-6.

19. Wilkinson TMA, Donaldson GC, Hurst JR, et al. Early therapy improves outcomes of exacerbations of chronic obstructive pulmonary disease. Am J Respir Crit Care Med 2004;168:1298-303.

20. Sin DD, Wu L, Anderson JA, et al. Inhaled corticosteroids and mortality in chronic obstructive pulmonary disease. Thorax 2005;60:992-7.

21. Soriano JB, Vestbo J, Pride NB, et al. Survival in COPD patients after regular use of fluticasone propionate and salmeterol in general practice. Eur Respir J 2002;20:819-25. 
22. Soriano JB, Kiri VA, Pride NB, et al. Inhaled corticosteroids with/without long-acting beta-agonists reduce the risk of rehospitalisation and death in COPD patients. Am J Respir Med 2003;2:67-74(8).

23. Suissa $\mathbf{S}$. Inhaled steroids and mortality in COPD: bias from unaccounted immortal time. Eur Respir J 2004;23:391-5.

24. Barr RG, Bourbeau J, Camargo CA, et al. Tiotropium for stable chronic obstructive pulmonary disease: a meta-analysis. Thorax 2006;61:854-62.

25. Ram FSF, Rodriguez-Roisin R, Granados-Navarrete A, et al. Antibiotics for exacerbations of chronic obstructive pulmonary disease. Cochrane Database Syst Rev 2006;(2):CD004403. doi:10.1002/14651858. CD004403.pub2.

26. Wood-Baker RR, Gibson PG, Hannay M, et al. Systemic corticosteroids for acute exacerbations of chronic obstructive pulmonary disease. Cochrane Database Syst Rev 2005:(1): CD001288.

27. Griffiths TLB. Results at 1 year of outpatient multidisciplinary pulmonary rehabilitation: a randomised control led trial (published erratum appeats in Lancet 2000;355:1280). Lancet 2000;355:362-8.

28. Cockcroft A, Bagnall P, Heslop A, et al. Controlled trial of respiratory health worker visiting patients with chronic respiratory disability. BMJ 1987;294:225-8.
29. Monninkhof $\mathbf{E}$, van der Valk $\mathrm{P}$, van der Palen $\mathrm{K}$, et al. Effects of a comprehensive self-management programme in patients with chronic obstructive pulmonary disease. Eur Respir J 2003;22:815-20.

30. Bourbeau J, Julien M, Rouleau M, et al. Reduction of hospital utilization in patients with chronic obstructive pulmonary disease. Arch Intern Med 2003; 163:585-91.

31. Gibson PG, Powell $H$, Coughlan J, et al. Self management education and regular practitioner review for adults with asthma (Cochrane Review); Oxford: Update Software, The Cochrane Library, 2003:issue 1.

32. Gibson PG, Powell H. Written action plans for asthma: an evidence-based review of the key components. Thorax 2004;59:94-9.

33. Gallefosse F, Bakke PS. Impact of patient education and self-management on morbidity in asthmatics and patients with chronic obstructive pulmonary disease. Respir Med 2000;94:279-87.

34. Watson PB, Town Gl, Holbrook N, et al. Evaluation of a self-management plan for chronic obstructive pulmonary disease. Eur Respir J 1997;10:1267-71.

35. Turnock AC, Walters EH, Walters JAE, et al. Action plans for chronic obstructive pulmonary disease. Cochrane Database Syst Rev 2005;(4): CD005074. doi 10.1003/ 14651858.CD005074.pub2.

\section{Lung alert}

\section{IP-10 as a biomarker for rhinoviral infections in asthma}

Asthma exacerbations are most commonly triggered by viruses, particularly rhinovirus. There is currently no biomarker that can be used to predict that a virus has triggered an exacerbation.

This group studied bronchial epithelial cells (BECs) obtained by bronchoscopy from 10 healthy controls and 10 patients with asthma who had never received inhaled corticosteroids. The epithelial cells were cultured and exposed to rhinovirus 16. The supernatants were measured for various cytokines including interferon- $\gamma$-induced protein 10 (IP-10) by FACs analysis.

There was a significant increase in IP-10, RANTES, interleukin (IL)-6, IL-8 and tumour necrosis factor $\alpha$ from baseline, which peaked at $48 \mathrm{~h}$ after infection. There was no significant difference between patients with asthma and controls. Pretreatment of the BECs with dexamethasone did not significantly reduce the release of IP-10. Rhinovirus replication was significantly greater in BECs of subjects with asthma than controls, and there was a positive correlation between IP-10 release and viral concentrations.

The authors went on to investigate whether acute virus-induced asthma could be differentiated form non-infective acute asthma. These patients were not steroid naïve. They found that patients with acute virus-induced asthma had significantly increased IP-10 levels compared with those with non-viral acute asthma. Viral infections were also found to be associated with lower forced expiratory volume in $1 \mathrm{~s}$. Individuals with acute rhinoviral infection specifically had significantly increased IP-10 levels, and a level of 168-1916 pg/ml increased the likelihood of rhinoviral infection more than twofold.

It appears that rhinoviral infection initiates an inflammatory response with marked release of IP-10, and this correlates with rhinovirus replication. The authors conclude that IP-10 may therefore be a useful clinical marker to identify rhinovirus-induced asthma and may be a potential therapeutic target for the future.

- Wark PAB, Bucchieri F, Johnston SL, et al. IFN- $\gamma$-induced protein 10 is a novel biomarker of rhinovirus-induced asthma exacerbations. J Allergy Clin Immunol 2007;120:586-93

\section{Jennifer K Quint}

Correspondence to: J K Quint, Clinical Research Fellow and SpR, University College London, London, UK; j.quint@medsch.ucl.ac. uk 